\title{
Encontros reflexivos dialogais (ERD): um recurso metodológico possível nas ciências humanas e sociais
}

\author{
Erivania Melo de Morais*
}

\section{Resumo}

Este trabalho tem como finalidade discutir inicialmente os Encontros Reflexivos Dialogais - ERD ${ }^{1}$ - como recursos metodológicos possíveis nas ciências humanas e sociais. A sua constituição tem fundamentação nas concepções de grupos focais, a partir de Gatti (2012) e Barbour (2009) e nos grupos reflexivos desde Formiga e Barbosa (2008), tendo como base epistêmica a abordagem multirreferencial, que permitiu o seu desenvolvimento a partir da bricolagem e de autorizar-se enquanto um processo criativo da pesquisa, levando em consideração as especificidades e complexidades da investigação científica. Assim, para melhor sistematizar a compreensão do ERD, vamos apresentá-lo em dois momentos a saber: o primeiro "A ressignificação metodológica: grupos focais e reflexivos como ponto de partida" e, em segundo, "Os Encontros Reflexivos Dialogais como recurso metodológico nas ciências humanas e sociais”, dessa forma evidenciamos a relevância desse recurso como um caminho possível para a pesquisa social, que suscita dois movimentos: primeiro, de autorização dos participantes e, segundo, de apreender os seus sentidos e significados em relação a uma temática.

Palavras-chave: Grupo focal. Grupo reflexivo. Metodologia alternativa. Multirreferencialidade. Encontros Reflexivos Dialogais.

Universidade Federal do Rio Grande do Norte

Recurso metodológico utilizado na nossa pesquisa de doutorado no Programa de Pós-Graduação em Ciências Sociais da Universidade Federal do Rio Grande do Norte/UFRN, que está em fase de desenvolvimento, mas que tem se mostrado como um potencial possível para a apreensão dos sentidos e significados acerca de algo, sobre processos formativos, reflexivos e constituídos de modo coletivo a partir da imersão do campo de pesquisa. 


\section{Dialogical reflective encounters (ERD): a possible methodological resource in human and social sciences}

\section{Abstract}

This paper aims to initially discuss the Dialogal Reflective Encounters - ERD - as possible methodological resources in the human and social sciences. Your constitution is based on the conceptions of focus groups, based on Gatti (2012) and Barbour (2009) and on the reflective groups based on Formiga and Barbosa (2008), based approach Multireferential, which allowed its development from the bricolage and to authorize itself as a creative process of research, taking into account the specificities and complexities of scientific research. Thus, to better systematize the understanding of the ERD, we will present it in two moments, namely: the first "Methodological resignification: focal and reflexive groups as a starting point" and secondly "Dialogal Reflective Encounters" as a methodological resource in the humanities and Thus, we highlight the relevance of this resource as a possible way for social research, which raise two movements, first of authorization of the participants and second to grasp their senses and meanings in relation to a thematic.

Keywords: Focus group. Reflective group. Alternative methodologies. Multireferentiality. Dialogical Reflective Meetings.

\section{Encuentros reflexivos dialógicos (ERD): un posible recurso metodológico en ciencias humanas y sociales.}

\section{Resumen}

Este artículo tiene como objetivo discutir inicialmente los Encuentros reflexivos dialógicos (ERD) como posibles recursos metodológicos en las ciencias humanas y sociales. Su constitución se basa en las concepciones de grupos focales, basados en Gatti (2012) y Barbour (2009) y en los grupos reflexivos desde Formiga y Barbosa (2008), teniendo como base epistémica el enfoque multirreferencial, que permitió su desarrollo desde bricolage y autorizarse como un proceso creativo de investigación, teniendo en cuenta las especificidades y complejidades de la investigación científica. Por lo tanto, para sistematizar mejor la comprensión del RDE, lo presentaremos en dos momentos, a saber: la primera "resignificación 
metodológica: grupos focales y reflexivos como punto de partida" y, en segundo lugar, "los encuentros reflexivos de diálogo como recurso metodológico en el humanidades y ciencias sociales ", destacando así la relevancia de este recurso como una posible forma de investigación social, que plantea dos movimientos: primero, la autorización de los participantes y, segundo, comprender sus sentidos y significados en relación con un tema. Palabras clave: Grupo focal. Grupo reflexivo. Metodología Alternativa. Multireferencialidad. Encuentros Reflexivos Diálogicos.

\section{Introduzindo o debate}

Quando pensamos nos "Encontros Reflexivos Dialogais" ERD, estávamos num processo de estudos e reflexões acerca dos possíveis recursos metodológicos que seriam desenvolvidos na nossa pesquisa doutoral no programa de pós-graduação em ciências sociais da Universidade Federal do Rio Grande do Norte, que está em andamento e cujo objeto de pesquisa são "os sentidos da profissão de professor em ciências sociais constituídos por licenciandos durante o percurso acadêmico" e entre os recursos que, inicialmente, pensamos estavam: revisão bibliográfica, questionários, entrevistas, que foram utilizados na nossa pesquisa de mestrado em educação pelo programa de pós-graduação em educação da UFRN, e cuja dissertação teve como título: "Representação social e docência: um estudo sobre a formação dos licenciandos da UFRN a partir do Programa Institucional de Bolsa de Iniciação à Docência (PIBID)". Para a nossa pesquisa doutoral, além desses que já havíamos usado, acrescentava-se o grupo focal, que a princípio era aquilo que estávamos a fim de desenvolver desde uma formação sobre a profissão docente em ciências sociais. Entretanto, no decorrer da pesquisa e ao nos encontrarmos com a abordagem multirreferencial, percebemos que o grupo focal não mais nos movimentava à reflexão dos processos formativos, porque nos levava a repetir aquilo que já era realizado no curso de formação em ciências sociais, por exemplo, debates a partir de eixos temáticos prontos e de questões norteadoras. O que não deixa de ser algo relevante para o processo formativo, mas que não estava atendendo às demandas da nossa pesquisa doutoral e precisávamos avançar do ponto de vista metodológico. 
Assim, quando passamos a nos debruçar de fato na abordagem multirreferencial a partir de Ardoino (1998) e ao refletir sobre o fazer ciência em Borba (1998), que nos sinaliza que é na constituição do campo de pesquisa que se elabora in loco as metodologias e não o contrário, passamos a repensar se de fato o grupo focal atenderia ao que encontraríamos no campo.

De fato, ao pensarmos os ERD, pensamos no sentido formativo convencional em que levaríamos alguns eixos temáticos ou questões a partir do nosso objeto e objetivos, mas após entender e compartilhar desse entendimento, de que os caminhos devem ser constituídos desde a nossa relação com o campo de pesquisa, passamos a não estabelecer o que seria discutido, e só pensaríamos nas possibilidades reflexivas quando estivéssemos junto aos nossos participantes, que conduziriam o que seria dialogado e debatido nos encontros.

Assim, este artigo tem como objetivo discutir inicialmente os Encontros Reflexivos Dialogais - ERD, como recursos metodológicos possíveis nas ciências humanas e sociais, e entendemos o mesmo como um recurso flexível e não engessado, que se constitui a partir de contextos e situações em que a pesquisa se desvela enquanto complexa, ou seja, é um recurso que se adapta às possibilidades criativas de cada pesquisador imbricar no campo de pesquisa que passa a ressignificar os caminhos desde o seu objeto e objetivos.

Nesse sentido, vamos apontar as bases teóricas dos Encontros Reflexivos Dialogais e posteriormente vamos elucidar algumas indicações mais singulares dos ERD, por exemplo, um preâmbulo para se pensar seus caminhos, que não podem ser tidos como fechados, mas como algo aberto para o processo de ressignificação, sendo um recurso possível para as pesquisas em ciências humanas e sociais e entendida como um caminho formativo complementar para os cursos de graduação, ${ }^{2}$ que podem suscitar reflexões e os

A nossa pesquisa foi realizada com os alunos da Licenciatura em ciências sociais, mas esse recurso pode ser utilizado como recurso formativo para os cursos de bacharelado e tecnológico de modo a suscitar nos alunos interesse em aprofundar, dialogar e refletir sobre suas práticas profissionais. 
diálogos acerca da relação teoria e prática como indissociáveis para se pensar a prática profissional de forma crítica.

Deste modo, no próximo ponto vamos explicitar as bases teóricas que nos movimentaram a pensar na possibilidade dos Encontros Reflexivos Dialogais, como recursos metodológicos.

\section{A ressignificação metodológica: grupos focais e grupos reflexivos como pontos de partida}

Ao nos aproximarmos dos grupos focais em nossos estudos doutorais, passamos a compreender que, apesar de sua estrutura ser de um todo relevante, não era o que pretendíamos realizar com os participantes da nossa pesquisa, tendo em vista que já estávamos imersos nas contribuições da abordagem multirreferencial, que a todo momento nos chamava para um processo de autorização e de nos colocarmos enquanto sujeitos coautores e não apenas como agentes reprodutores de instrumentalidades metodológicas, mas que iniciássemos um caminhar de aprendizagens possíveis, de nos permitir a pensar, a repensar e a ressignificar os nossos recursos metodológicos.

Mas é sabido que não é possível ressignificar algo que não conhecemos, assim, entendemos os grupos focais como centrais, para o nosso movimento de ressignificação do fazer metodológico, junto ao grupo focal, tivemos o encontro com um texto que nos inquietou intitulado de "Grupo Reflexivo: uma estratégia de pesquisa formativa em educação" problematizado por Formiga e Barbosa (2008), que apresentava nova forma de organização de grupos em que motivava os participantes a explicitarem as impressões que tinham dos autores que foram distribuídos no primeiro momento. Essa dinâmica foi realizada em dois encontros, um de contextualização e apresentação de textos, que perpassavam três perspectivas, a saber: Na primeira, usou-se o conflito funcional, discutindo a relação entre o administrativo e o pedagógico no interior da escola. $\mathrm{Na}$ segunda, tratava da interconexão para a gestão escolar, que buscava pensar o pedagógico como ação e relação mediada pela comu- 
nicação intersubjetiva. E, por fim, na terceira estava a abordagem multirreferencialidade. Buscando a partir de suas análises pensar a gestão escolar como plural (FORMIGA; BARBOSA, 2008).

Esses dois recursos foram bases para que pensássemos o movimento do dos ERD como um caminho flexível, em que cada pesquisador precisa ser constituído como um processo criativo, e que permite duas possibilidades, que podem ser entendidas nas suas especificidades, mas que são relacionais, que é permitir a apreensão dos sentidos, dos significados, dos sentimentos, das ideias, das concepções, dos pontos de vistas que cada participante tem, mas também é formativa porque permite que se autorizem, criem, desenvolvam, ressignifiquem o processo formativo.

Assim, localizando melhor os grupos focais, podemos compreendê-los como grupos, que possuem entre seis a doze participantes e, a partir de questões, problemas ou de temáticas, discutem sob o comando de um facilitador, que não pode se implicar, que precisa estimular que os participantes discutam ao máximo as problematizações levantadas, ou em relação aos temas propostos, para que esse facilitador possa apreender as visões e opiniões convergentes ou não.

Desse modo, Barbour (2009), ao desenvolver as suas pesquisas com grupos focais, assinalava algumas preocupações em relação a esse recurso, fosse em relação ao risco de contribuir para "meias verdades pedagógicas", 3 que tendem a contaminar o esforço da prática da pesquisa empírica, ou ainda no que tange à perspectiva de entender que, muitas vezes, o que funciona para um expoente de grupos focais pode não funcionar para outro, ou seja, apesar do esforço de obter uma discussão, pode-se cair naqueles velhos modelos ou manuais de como fazer algo, como se toda pesquisa se encaixasse no que está sendo proposto. Assim, as

A autora faz referência a Paul Anthony Atkinson, professor emérito de Sociologia na Universidade de Cardiff, País de Gales no Reino Unido, em Narrative turn or Blind Alley?, publicado em Qualitative Health Research. 
[...] abordagens desenvolvidas para lidar com os requisitos de um projeto de pesquisa específico podem não ser bem convertidos para outro, em que os dados estiverem sendo produzidos com outro proposito ou que esteja vinculado a outro grupo de pessoas (BARBOUR, 2009, p. 20).

Barbour (2009), ao pensar numa definição do grupo focal, traz que em muitos casos são vistos com termos como: entrevista de grupo; entrevista de grupo focal; discussão de grupo focal e que são usados de forma intercambiável. Esses termos baseiam-se em gerar e analisar a interação entre os participantes em vez de perguntar a mesma questão ou lista de questões para cada integrante do grupo. Ou seja, para a constituição dos grupos focais é necessário ter definido eixos, ou questões que norteiem o debate, e essas devem ser previamente pensadas. Os ERD não são entrevistas em grupo, mas diálogos reflexivos em que as problematizações surgem da relação e do diálogo entre os participantes, não há nada preestabelecido.

Gatti (2012), ao pensar os grupos focais, sinaliza que auxiliam no clareamento das atitudes, linguagem da comunicação entre os membros do grupo; identificam as normas do grupo; oferecem insight sobre a relação entre o funcionamento do grupo e processos sociais na articulação de informação; encorajam uma conversação aberta entre os tópicos; facilitam a expressão de ideias. Assim:

O trabalho com grupos focais permite compreender processos de construção da realidade por determinados grupos focais, compreender práticas cotidianas, ações e reações e fatos e eventos, comportamentos e atitudes, constituindo uma técnica importante para o conhecimento das representações, percepções, crenças, hábitos, valores, restrições, preconceitos, linguagens e simbologias prevalentes no trato de uma dada questão por pessoas que partilham alguns traços em comuns, relevantes para o estudo do problema visado (GAT'TI, 2012, p. 11).

Gatti (2012) ainda sinaliza que os grupos focais são relevantes porque ajudam na obtenção de perspectivas diferentes da mesma questão e também permitem a compreensão de ideias partilhadas por pessoas no dia a dia e dos modos pelos quais os indivíduos são influenciados pelos outros. 
Compartilhando do que Gatti (2012) explicita, os ERD buscam um movimento de permitir que os participantes nos diálogos coloquem suas ideias, crenças, percepções, mas procura ir além desse processo, possibilitando o processo de autorização e de se perceber como parte integrante da formação.

Pensar nesse movimento de ressignificação perpassa pelo entendimento de que se constituiu como um processo de acúmulo de repertórios e conhecimentos acumulados ao longo de uma trajetória de pesquisa no âmbito da formação docente, em que não descartamos os apontamentos dos anteriores, mas que, no nosso devir criativo de pensar o nosso objeto, entendemos que seria necessário uma nova forma de pensar esses grupos, não como focalizados, ou com eixos e questões previamente prontas em que se refletia o que foi instituído por outro, mas que buscava se ampliar em encontros que fossem reflexivos no que tange à própria ação do sujeito envolvido como autor e não apenas como agente de uma mecânica pronta, e ainda que permitissem ao grupo dialogar sobre determinada temática que partisse do seus interesses, das suas motivações e daquilo que fizesse sentido para a sua formação. Assim, pensamos nos Encontros Reflexivos Dialogais como um recurso que como uma colcha de retalho foi incorporando conhecimentos de outros e se constituindo e se ressignificando como um encontro em que autoriza, que permite o outro se perceber.

\section{Esquema.}

Processo de constituição dos ERD
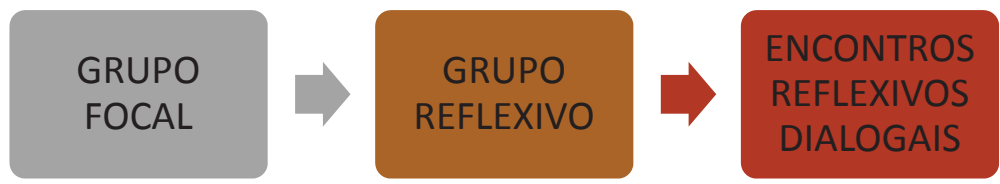

Fonte: Elaborado pela autora.

Os ERD surgem não como algo que recusa, ou que nega o outro, mas como uma possibilidade de permitir aos pesquisadores 
que se impliquem e que ressignifiquem o movimento que desejam conduzir nos seus processos formativos em grupo, que coloquem seu tom, ou que se autorizem a criar.

Nesse sentido, vamos no próximo tópico elucidar alguns apontamentos sobre os Encontros Reflexivos Dialogais e de como a sua flexibilidade pode se ajustar a pesquisas diversas dentro da área das ciências humanas e sociais. É preciso que cada pesquisador entenda que esses encontros devem ser propostos de forma reflexiva e dialogada entre os participantes da pesquisa como um processo coletivo.

\section{Os encontros reflexivos dialogais como recurso metodológico nas ciências humanas e sociais}

Os Encontros Reflexivos Dialogais - ERD - precisam ser entendidos antes de qualquer coisa como um processo de autorização, que é flexível, e que pode se ajustar a pesquisas que busquem para além de uma discussão com base em temática ou questão, suscitar um processo formativo em que os participantes sejam parte e se sintam parte do momento dialogado.

Os participantes são centrais para o desenvolvimento dos ERD, porque são eles e suas reflexões e diálogos que conduzirão os próximos momentos e não o contrário, se o mediador já leva as questões prontas e os eixos prontos, se trata de grupo focal, se levam eixo, problemas e textos para discutir e perguntar o que os participantes acham que o autor está falando, pode ser compreendido como grupo reflexivo.

Nos ERD, a teoria e a prática se imbricam, elas surgem no diálogo, e são desveladas no processo, óbvio que é necessário ter teorias que norteiem os pensamentos, mas não adianta ler e discutir o texto e os autores sem ler a realidade e pensar a realidade a partir da teoria. É isso que os ERD propõem, essa não dissociação entre teoria e prática. Nos encontros, essas duas perspectivas devem ser conduzidas de modo relacional e dialético.

Assim podemos sinalizar que os ERD 
- Pressupõem uma temática geral que normalmente estará ligada a um objeto de pesquisa;

- Precisam ser observados com motivadores para a reflexão dos participantes;

- São momentos de reflexão coletiva, em que os participantes suscitam o que vai ser debatido nos próximos encontros;

- Inicialmente, podem ser desenvolvidos por meio de uma atividade de acolhida dos participantes, e esse momento deve ser algo que motive e que os leve a se sentir parte do processo, não como aqueles que estão passando por uma formação, ou por entrevistas em grupo, mas que se sintam parte do momento de constituição dos Encontros;

- Devem dialogar com a teoria e a prática como relacional, permitindo a aproximação de uma análise da realidade social;

- Precisam evidenciar seu caráter autorizador, ou seja, em que os participantes se percebem como ativos, e como aqueles que também ensinam e não apenas aprendem.

Nesse sentido, podemos entender que os ERD são de um todo complexo, porque buscam, a partir do seu processo, dois movimentos, um que seria o de autorizar o outro, que, de acordo com Barbosa (2004), é a capacidade de fazer-se a si mesmo, e que é constituído na relação intersubjetiva com o outro e, que a partir desse processo, passa a se reconhecer e se sentir como aquele que constitui seus sentidos, que não apenas reproduzem o que foi instituído por uma coletividade, e o segundo movimento, é a possibilidade de, a partir do que está sendo levantado pelos participantes, através das questões, das inquietações, dos eixos sugeridos nos diálogos, elucidar seus pontos de vista, suas visões, seus significados, seus sentidos, ou seja, desvelar como estão pensando aquilo que está sendo dialogado. 
Destarte, consideramos relevante sinalizarmos algumas características de cada processo de modo sistematizado, assim:

\section{Quadro - Processo de constituição do ERD}

\begin{tabular}{|c|c|c|}
\hline OCAL & GRUPO REFLEXIVO & ERD \\
\hline $\begin{array}{l}\text { - O roteiro elaborado } \\
\text { como forma de orientar e } \\
\text { estimular a discussão; } \\
\text { - O grupo focal deve ter } \\
\text { em sua constituição um } \\
\text { problema de pesquisa bem } \\
\text { definido, assim como as } \\
\text { questões a serem levadas ao } \\
\text { grupo; } \\
\text { - Os grupos focais ajudam } \\
\text { a: clarear as atitudes, lingua- } \\
\text { gem, facilitar a expressão de } \\
\text { ideias; } \\
\text { - Os grupos focais têm por } \\
\text { objetivo captar, a partir das } \\
\text { trocas realizadas no grupo, } \\
\text { conceitos, sentimentos, ati- } \\
\text { tudes; } \\
\text { - Os participantes devem } \\
\text { ter alguma vivência com o } \\
\text { tema a ser discutido } \\
\text { GATTI (2012). }\end{array}$ & $\begin{array}{l}\text { Elaboração de etapas: Se- } \\
\text { leção de sujeitos; } \\
\text { - Preparação dos textos } \\
\text { para o primeiro encontro; } \\
\text { - Períodos para leituras } \\
\text { e elaboração de um texto } \\
\text { por parte dos profissio- } \\
\text { nais convidados e direcio- } \\
\text { nador do futuro debate; } \\
\text { - Discussões focalizadas } \\
\text { tendo o horizonte pro- } \\
\text { posto pela entrevista cole- } \\
\text { tiva focalizada; } \\
\text { - O movimento metodo- } \\
\text { lógico coloca o pesqui- } \\
\text { sador não com um olhar } \\
\text { solto, ou engessado, fe- } \\
\text { chado, mas pressupõe um } \\
\text { olhar contextualizado; } \\
\text { - Utilização da perspecti- } \\
\text { va multirreferencial para } \\
\text { se ter uma reflexão plural } \\
\text { FORMIGA; BARBOSA } \\
\text { (2008). }\end{array}$ & $\begin{array}{l}\text { - É preciso definir um } \\
\text { tema geral, que normal- } \\
\text { mente se concatena com } \\
\text { o objeto de pesquisa, ou } \\
\text { é o próprio objeto de pes- } \\
\text { quisa; } \\
\text { - Não é focalizado; } \\
\text { - Não precisa ter questões } \\
\text { problemas ou eixos } \\
\text { previamente definidos, } \\
\text { esses podem ser desvelados } \\
\text { nos encontros; } \\
\text { - Podem ser criado am- } \\
\text { bientes alternativos para os } \\
\text { diálogos reflexivos; } \\
\text { - Buscar ser ao mes- } \\
\text { mo tempo autorizador e } \\
\text { apreender os sentidos e } \\
\text { significados, pontos de vis- } \\
\text { tas e reflexões; } \\
\text { - Pauta-se na abordagem } \\
\text { multirreferencial e na com- } \\
\text { plexidade. }\end{array}$ \\
\hline
\end{tabular}

Fonte: Elaborado pela autora.

É possível observar com esse quadro, como o grupo focal e o grupo reflexivo foram relevantes para pensarmos o ERD, que tem como entendimento não a negação nem o descarte das demais perspectivas, mas, ao contrário, assumir que, a partir dele, pensamos e ressignificamos os caminhos criativos de uma pesquisa, em que não há como encaixarmos pesquisas em gavetas, pois as 
reflexões precisam ser encaradas como espaços coletivos onde eixos temáticos, eixos discursivos, questões problematizadoras ou ainda os diálogos reflexivos sejam constituídos dentro de uma perspectiva coletiva, em que todos a partir de suas inquietações em relação a uma temática geral possam sinalizar o que mais os angustia e os levar a refletir sobre isso.

Esse recurso ainda está em desenvolvimento, como salientamos no início deste texto, faz parte da nossa pesquisa de tese e pretendemos posteriormente sinalizar outras reflexões mais aprofundadas acerca desse recurso que intitulamos de "Encontros Reflexivos Dialogais".

\section{Considerações finais}

Neste texto, fomos convidadas de modo bem preambular a tentar explicitar como estamos passando por um processo criativo de pensar os caminhos metodológicos de uma pesquisa doutoral. Vimos que, a partir dos nossos estudos sobre o grupo focal e o grupo reflexivo, surgiu a necessidade de repensarmos e ressignificarmos recursos ricos, mas que não nos movimentavam, ou seja, o que gostaríamos de realizar na nossa pesquisa se distanciava de ambos e, a partir disso, passamos a pensar, a repensar e a se autorizar num processo de bricolagem que, como salienta Barbosa (1998), admite perspectivas múltiplas em que o pesquisador deve se desenvolver autonomamente produzindo conhecimento e não apenas reproduzindo. Borba (1998), ao pensar em bricolagem, a coloca como uma composição metodológica, quer dizer, se refere, portanto, ao criar no campo de pesquisa os caminhos a serem percorridos e, assim, estamos tentando desenvolver nossa tese de doutorado, como um processo criativo que se constitui no caminho ao caminhar.

Nesse sentido, salientarmos que a abordagem multirreferencial foi o salto qualitativo da nossa posição epistêmica de pensar o mundo e a realidade. Não nos limitando a um olhar homogêneo, mas buscando apoio numa perspectiva plural e heterogênea para pensar o objeto da pesquisa, porque uma só concepção ou abor- 
dagem não dão conta de pensar objetos complexos como os que propomos investigar que está no campo da educação.

Nossa pesquisa e nossa trajetória da pesquisa se pautam na formação docente e no ensino de sociologia, onde buscamos pensar as práticas, as metodologias, as perspectivas teóricas dentro das discussões sociológicas, que são de todo complexas e plurais. Assim, buscamos, a partir dessa base sociológica e com a abordagem multirreferencial, ampliar nosso campo de visão e de análise da realidade acerca das especificidades do campo educacional como um todo, e que isso nos implique a nos movermos e a desenvolvermos reflexões sobre uma prática mais ativa e significativa para os processos de aprendizagem.

\section{Referências}

BARBOSA, Joaquim Goncalves (Coord.). Multirreferencialidade nas ciências e na educação. São Carlos: Editora da UFSCar, 1998.

BARBOSA, Joaquim Gonçalves. O pensamento plural e a instituição do outro. Dossiê Multirreferencialidade e Educação. Educação \& Linguagem. Ano 7, n. 9, p. 13-25, jan./jun. 2004.

BARBOUR, Rosaline. Grupos Focais. Trad. Marcelo Figueiredo Duarte. Porto Alegre: Artmed, 2009.

BORBA, Sergio da Costa. Aspecto do conceito de Multirreferencialidade nas ciências e nos espaços de formação. In: BARBOSA, Joaquim Gonçalves. Reflexões em torno da abordagem Multirreferencial. São Carlos: EDUFScar, 1998, p. 11-19.

FORMIGA, Maria das Graças Freire; BARBOSA, Joaquim Gonçalves. Grupo Reflexivo: uma estratégia de pesquisa formativa em educação, 2008. In: . Cadernos de Educação reflexões e debates. O sujeito na escolha: incursões metodológicas e perspectivas de análise. Universidade Metodista de São Paulo, jul./dez. 2008, n. 15.

GATTI, Bernardete Angelina. Grupo Focal na pesquisa em ciências sociais e humanas. Brasília: Liber Livro Editoria, 2012. 
MORAIS, Erivania Melo de. Representação Social e docência: um estudo sobre a formação de licenciandos da UFRN (Campus Central) a partir do programa institucional de bolsas de iniciação à docência (PIBID). Natal, 2017, $221 \mathrm{~s}$. Dissertação (Mestrado em educação). Universidade Federal do Rio Grande do Norte. Centro de Educação. Programa de Pós-Graduação em Educação.

\section{Erivania Melo de Morais}

Universidade Federal do Rio Grande do Norte

Licenciada em Ciências Sociais CCHLA/UFRN. Mestre em Educação pelo PPGED/UFRN. Cursa Serviço Social pelo CCSA/UFRN e Doutorado em Ciências Sociais PPGCS/CCHLA/UFRN. Experiência como professora substituta do IFRN/Campus Apodi/RN. Áreas de Interesse: Sociologia e Sociologia da Educação (Ensino de sociologia); Teoria sociológica; Educação, Formação Docente, Políticas Públicas (Educação e Social), movimentos sociais; Interdisciplinaridade; Representações Sociais e Multireferencialidade. moraiserivania@gmail.com

Submetido em: 7-11-2019

Aceito em: 15-11-2019 